\title{
Modern infrastructure and sustainable socio- economic development of the region
}

\author{
Vladimir Sulimin, Vladislav Shvedov, and Maya Lvova* \\ Ural State University of Economics, Yekaterinburg, Russia
}

\begin{abstract}
In terms of a modern economic science, the basis of the term "region" is any key feature, aims at reflecting the integrated territory's allocation. Such indicator can include the geographic location, the economic relationships, and the management activities particularity. The article presents the basic concepts, describes the key functions, features of the structure totality, systems and services located on the territory of a certain administrative unit, designed to ensure a high level of material production efficiency and standards of living. The region economic development dependence on the infrastructure development level as well as its importance for the social and economic spheres of public life are identified.
\end{abstract}

\section{Introduction}

For providing a high-quality region functioning, as well as the normal life of its population, the infrastructure is needed, viewed as a complex of structures, systems, services, on the basis of which the main branches of material production develop in order to meet the needs of the citizens. There are two types of infrastructure: 1) economic type and 2) social one. The main infrastructure goal is focused on ensuring a stable growth and development of the territory.

Development in terms of the economy means a constant improvement in the living conditions of the population, including the growth of: a) income and products consumption; b) the level of education and medical care; c) self-respect, mutual respect of people as a consequence of determined social, political, and economic relationships; d) the degree of personal freedom due to a high-quality supply of goods and services for the citizens [6].

Thus, the region development should be considered as a progressive change in its structure, namely, economy, population, territory, material and information contacts, space (configuration, areas, complexes). Positive changes are also expected in public consciousness, the traditions of a society, and people's habits. The economic potential of the territory is the basis for improving the living standards of the citizens, their labor, living and recreation conditions.

The most striking characteristics of the development process of a particular integral territory should embrace versatility, inequality, asynchrony, cyclicality and staging. To

\footnotetext{
* Corresponding author: 1mi@usue.ru
} 
evaluate it, a complex criteria system is required for assessing a concrete territory infrastructure.

\section{Material and methods}

The determining factors and conditions for a separate territorial socio-economic system development are the following [4]:

- a complex of relations between the region and its outside key economic objects;

- residents within the boundaries of the territory, as well as the part of the population that has the opportunity to carry out labor activities;

- interconnected production facilities located in close proximity to each other;

- structures and facilities for serving purposes, on the basis of which the administrative-territorial unit functions;

- natural components and properties used by people in the economic activity: sources of various energy types available for using them in the industry and everyday life; substances of mineral origin necessary for energy production as well as raw materials and suppliers; objects of flora and fauna; a fresh water;

- capital costs, energy losses associated with the operation of power transmission lines;

- fuel costs;

- the development level of science, engineering, capabilities, enterprises and organization resources;

- the enterprises saturation, human settlements, transport networks, shopping sites, determined by the stable, sustainable and effective relationships;

- the quality of monitoring, control, analysis, forecasting, planning, regulation of socio-economic processes carried out on the particular territory;

- a complex, emotional and psychological state of the population, reflecting people's satisfaction with their living standards.

\section{Results and discussions}

A high degree of efficiency in the region development is provided by specific conditions that enable to locate and develop the production: climate, terrain, natural resources (seas, rivers, lakes, plants, animals, minerals); composition, location, sexually mature structure of the population; birthrate, mortality; cultural, economic, political, scientific, technical, organizational factors determining the society development; procedure, terms, places of shipment, movement, passengers and cargo delivery ; the state of the labor market, socioeconomic and material well-being of individuals; the presence of organizations necessary for the normal life of people (shops, communications, post office, transport, outpatient clinics), institutions that provide social assistance to citizens in need; economic and geographical location; the possibility of protecting citizens and their property, supporting their social activity in the goods and services production, carrying out social and political work; level of migration attractiveness.

The set of conditions contributes to assessing the arrangement level of an integral territory. Furthermore, its systematic increase determines the transition of the region's economy to the path of the intensive development [5].

A close connection with certain opportunities and resources, a rigid connection with the territory, the organization particularity of the production sphere make the process of formation and development of regional infrastructure low: it is necessary to form a huge structures complex and activities providing the quality-oriented material production, free 
movement of different resources and goods as well as the required living standards of people. The ultimate process goal aims at forming such an infrastructure, the functioning of which will lead significantly to the manufacturing-based economy, to transfer direct free funds to improve the quality of the population life.

A regional infrastructure plays an important role in creating a set of conditions for the development of the economy, raising the population living standards, encouraging the small firm's activities, small enterprises in order to save on subsidiary production facilities, and to increase the competitiveness of the goods produced [2].

The infrastructure development through the significant investments into the underdeveloped territories attracts a private capital in the production sector, thus contributing to the economic region growth.

From the market relations point of view, the regional infrastructure has three key tasks, namely, distribution, communication and adjusted ones. In terms of solving the first problem, it is worth distributing various resources over the region territory, for example, labor, financial, commodity, material ones. To solve the second problem, an equivalent exchange of labor products is carried out: among things, services, and information. To cope with the third task, the balance of supply and demand is maintained on all the markets of a certain territory. Failure to carry out any of these actions leads to negative phenomena in the economy.

Any noticeable reconstruction in the regional infrastructure requires enormous costs due to such properties as: the servicing nature of its functioning; extremely heterogeneous density of structures with a wide variety of quantitative indicators (for example, capacity, intensity, throughput capacity); a long-established base that requires the addition of new elements over it. All this should be taken into account when planning the infrastructure areas development.

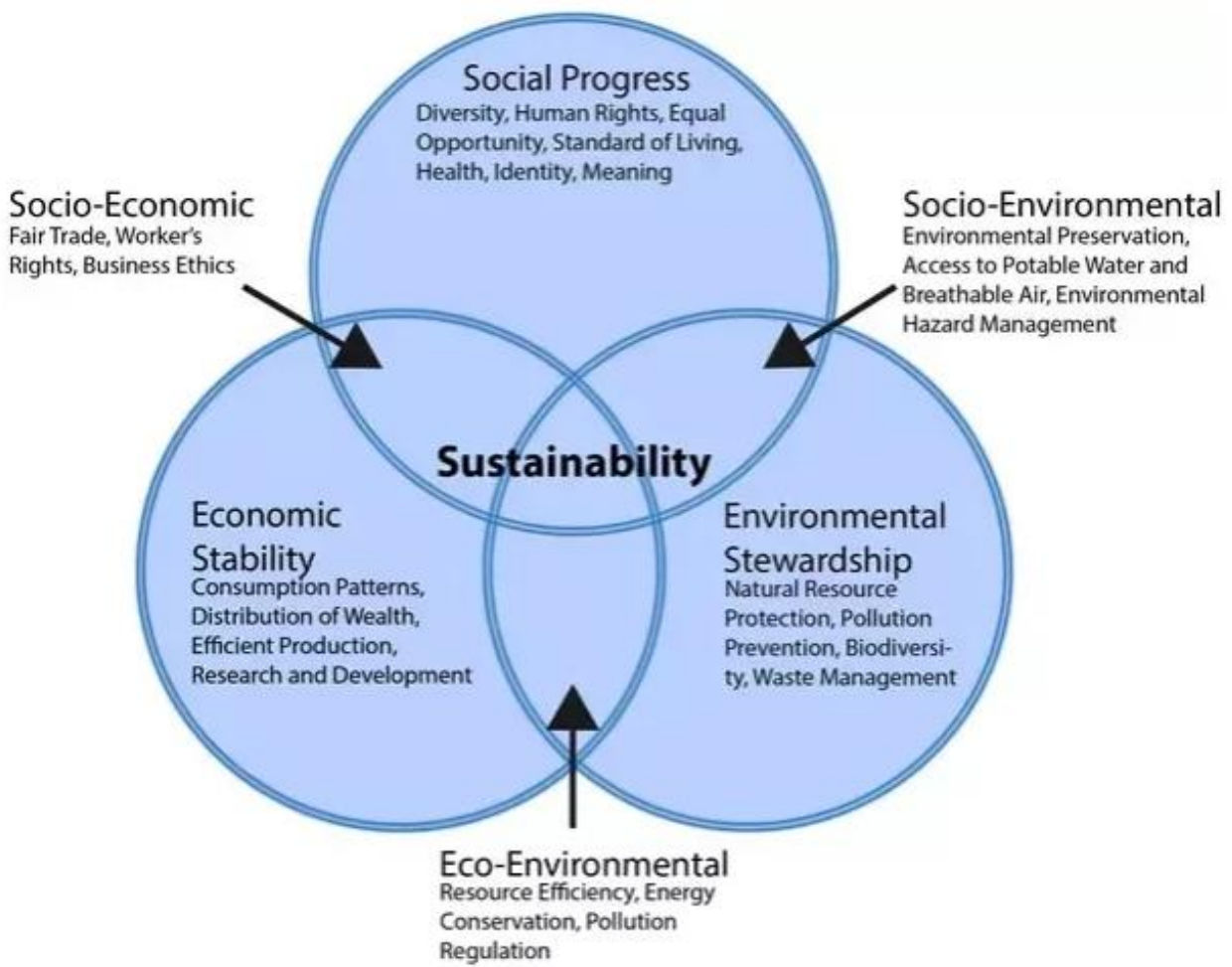

Fig. 1. Sustainable development framework 
The region infrastructure plays a very important functional role in the development of its economy due to the following reasons:

1. A deep social labor division contributes to complicating the production socialization processes, which, in its turn, has a positive impact of the general production conditions on the productive forces growth.

2. Due to the cross-industry nature of activity and the collective nature of consumption, as well as the multiplicity and significant consumer heterogeneity, the infrastructure does not possess a specific object to which its actions are directed.

3. The degree of the infrastructure development affects the key sectors efficiency of the economy [1].

It is worth mentioning that none of the infrastructure branches produces any values: all the costs of its formation are paid off after the start of work of the production spheres that have arisen thanks to it. At the same time, the infrastructure should be created before the economic development of the territory begins, since it is impossible to develop modern production in an unsettled region. All-round development of the economy distinguishes only those administrative-territorial units in which the infrastructure is highly developed.

Many experts are aware that: the competitiveness, socio-economic indicators of an integral territory directly depend on the level of its infrastructure development. The productions that effectively implement the developed structure and the region particularity, demonstrate a stable growth in labor productivity, contributing to an increase in the quality of the citizens living.

\section{Conclusion}

Analysis of the economic region infrastructure, including a whole range of interrelated elements (transport, agriculture, forestry and water management, information and communication interaction, environmental protection) enables to provide the comprehensive development of integral territories, improving the living standards of their citizens.

The research papers of the national economists as I.M. Mayergoz, E. B. Alaev, S. A. Debabov play an important role in studying the issues of the relationship between infrastructure and sustainable regions development; the above-mentioned authors considered the set of structures, buildings, systems, services necessary for the optimal functioning of material production, required for normal population living, as a basic prerequisite for managing the territory.

S.A. Heinman expressed a sectoral approach to the infrastructure essence, emphasizing that its main task is to service material production. V.A. Gaga, V.A. Shabarshev and V.G. Shekhovtsev point out even the rural residents' service. A. Yu. Sharipov considers that it is important to provide an infrastructure for the spiritual benefits of the population and to protect the environment itself. E.B. Dvoryadkin and E.E. Sapozhnikov paid attention to the evolutionary capabilities of the regional infrastructure, which have a positive effect on the development of the entire socio-economic system of the territory. M.D. Sharygin and A.M. Svistkov suggest that it is unacceptable to study the regional infrastructure out of touch with its spatial location.

Thus, at present there are several approaches to the study and analysis of the regions infrastructure among the specialists: productive, reproductive, industrial, territorial, systemic, and evolutionary ones. Nevertheless, there is no particular disagreement among the economists. All the experts admit that infrastructure is inseparable from any human formation and is involved in all the economic systems. A high level of its development and reliability guarantees the viability of the social and economic spheres of the territory, the 
competitiveness of the region within the framework of the country and the world [3]. Consequently, the infrastructure development in terms of forming and improving the region's economy is viewed as a top-priority goal.

\section{References}

1. V.A. Blaginin, Fundamental researches, 11(5), 979 (2016)

2. X.M. Gumba, S.S. Uvarova, A.G. Gamsonya, Real estate: economy, management, 2, 37 (2018)

3. O.V. Vaganova, L.I. Prokopova, G.G. Zabnina, Bulletin of the South-West State University, Series: Economics. Sociology. Management, 3(32), 109 (2019)

4. L.I. Prokopova, Scientific Bulletin of Belgorod State University, Series: Economics. Computer science, 46(1), 14 (2019)

5. Y.V. Lisova, Entrepreneur's Guide, 13(1), 130 (2020)

6. A.A. Mitus, Y.P. Garmashova, A.G. Baranov, A.M. Drebot, Creative economy, 14(12), 3259 (2020)

7. A. Aghahosseini, D. Bogdanov, C. Breyer, Energy Strategy Reviews, 28 (2020)

8. A.N. Dunets, I.B. Vakhrushev, M.G. Sukhova, M.S. Sokolov, K.M. Utkina, R.A. Shichiyakh, Entrepreneurship and Sustainability Issues, 7(2), 1217 (2019)

9. I. Fedulova, O. Voronkova, P. Zhuravlev, E. Gerasimova, M. Glyzina, N. Alekhina, Entrepreneurship and Sustainability Issues, 7(2), 1059 (2019)

10. D. Feliciano, Sustainable Development, 27(4), 795 (2019)

11. K. A. Gruia, R. Dobrea, C. Simion, C. Dima, A. Grecu, O.S. Hudea, D. Peptenatu, Sustainability (Switzerland), 11(22) (2019)

12. L. O. Juma, A. Khademi-Vidra, Sustainability (Switzerland), 11(17) (2019)

13. O. Kalenov, S. Kukushkin, R. Kamanina, E3S Web of Conferences, 105 (2019)

14. D. Karagiannis, T. Metaxas, Sustainability (Switzerland), 12(12) (2020)

15. S. Kukushkin, O. Kalenov, E3S Web of Conferences, 105 (2019)

16. M. Rajasekhar, S.R. Gadhiraju, A. Kadam, V. Bhagat, Arabian Journal of Geosciences, 13(2) (2020)

17. J. Xue, D. Gui, J. Lei, H. Sun, F. Zeng, D. Mao, Y. Liu, Catena, 179, 197 (2019) 